\title{
Successful Surgical Management of Radial Artery Pseudo Aneurysm Following Trans-radial Coronary Artery Intervention: Report of Two Cases
}

\section{Gauranga Majumdar ${ }^{1 *}$, Surendra Agarwal' ${ }^{1}$, Shantanu Pande ${ }^{1}$, Bipin Chandra ${ }^{1}$ and Aditya Kapoor ${ }^{2}$}

${ }^{1}$ Department of Cardiovascular and Thoracic Surgery, Sanjay Gandhi Post Graduate Institute of Medical Sciences, India ${ }^{2}$ Department of Cardiology, Sanjay Gandhi Post Graduate Institute of Medical Sciences, India

\begin{abstract}
Radial artery is now increasingly used as vascular access site for diagnostic and therapeutic procedures in cardiology practice. Though successful, it may be associated with vascular complications necessitating intervention. We report two cases of radial artery pseudo aneurysm one each arising out of diagnostic and therapeutic cardiac intervention. Though rare, successful management of such a complication is easier with radial artery as vascular access site as compared to femoral artery that is conventionally used access site for cardiac intervention procedures.
\end{abstract}

Keywords: Pseudo aneurysm; vascular injury; Coronary angiography; Percutaneous coronary artery angioplasty

\section{Introduction}

In recent times radial artery has emerged as the vascular access site for cardiac procedures [1]. This approach scores over the conventionally used femoral artery access on account of early mobilization and ease of procedure for the patient [2]. Though the incidence of blockage of the radial artery when used as vascular access is high, more serious complications like pseudo aneurysm are rare [3]. We report two cases of pseudo aneurysm formation after use of right radial artery as access to perform angiography in one case and coronary artery stenting in the other.

\section{Case 1}

A 52 yrs old lady presented with swelling in left wrist one month after undergoing a diagnostic coronary angiography through left radial artery. On examination there was a pulsatile $(1.5 \times 1.5 \mathrm{~cm})$ swelling seen in the course of radial artery (Figure 1). She had no other symptoms and there was no coronary artery disease seen in angiography. She was initially manged conservatively with compression bandage. Despite compression dressing, pseudo aneurysm increased in size. Doppler ultrasonography was done which confirmed it to be a pseudo aneurysm. Computed Tomography peripheral angiography was performed to see extent and width of neck of defect to plan surgical intervention (Figures 2A and 2B). Patient underwent successful primary repair of radial artery rent after excision of pseudoaneyrysm sac. Post-operative recovery was uneventful.

\section{Case 2}

A 72 yrs old lady with known triple vessel coronary artery disease, stable angina, underwent Tran's radial coronary artery angioplasty; three drug eluting stents were deployed in all the three major arteries. She developed pulsating swelling in the vascular access site in the next morning which was increasing in size (Figure 3 ). Proximal radial artery compression was applied using pneumatic device to prevent impending rupture as the tissues and skin over the aneurysm had thinned out [4]. She was referred to us for surgical repair. Under local anaesthesia radial artery psedonaeurysm was repaired successfully without any complication (Figure 4).

\section{Discussion}

Popularity of trans-radial route for cardiac catheterization and even subsequent therapeutic procedures rides on the easily accessibility, early mobilization, and reduced hospital stay and access site complications [5]. Though the incidence of radial artery occlusion is fairly high, other more serious complications like ischemia, nerve damage, bleeding and pseudo aneurysm formation are rare $[3,6]$. While the incidence of pseudo aneurysm formation at radial artery site is $0.1 \%$,

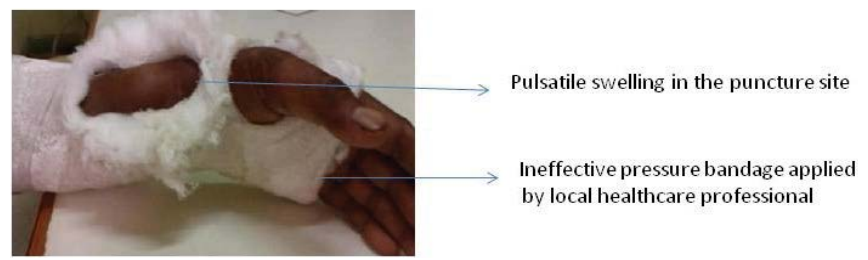

Figure 1: Radial Artery Pseudo-Aneurysm following Diagnostic Coronary Angiography.
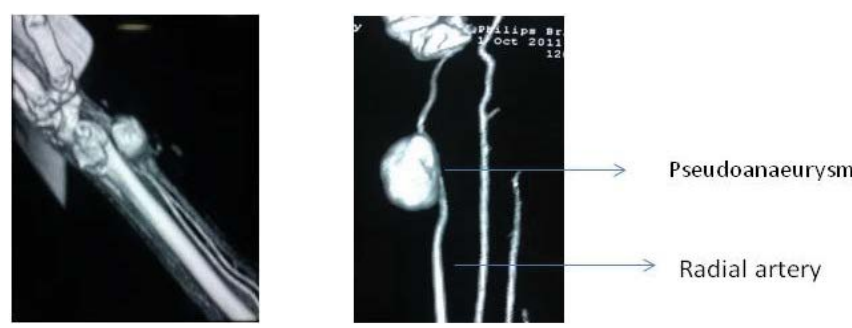

Figure 2: (A and B) Computarised Tomography Peripheral Angiography Showing Radial Pseudo-Aneuyrsm.

*Corresponding author: Gauranga Majumdar, Additional Professor, Department of Cardiovascular and Thoracic Surgery, Sanjay Gandhi Post Graduate Institute of Medical Sciences, India, Tel: +919415005757; Fax: +919415005757; E-mail: gaurangamajumdar@hotmail.com

Received March 06, 2016; Accepted April 28, 2016; Published May 09, 2016

Citation: Majumdar G, Agarwal S, Pande S, ChandraB, Kapoor A (2016) Successful Surgical Management of Radial Artery Pseudo Aneurysm Following Trans-radial Coronary Artery Intervention: Report of Two Cases. J Cardiovasc Dis Diagn S1: 001. doi:10.4172/2329-9517.S1-001

Copyright: (c) 2016 Majumdar G, et al. This is an open-access article distributed under the terms of the Creative Commons Attribution License, which permits unrestricted use, distribution, and reproduction in any medium, provided the original author and source are credited. 


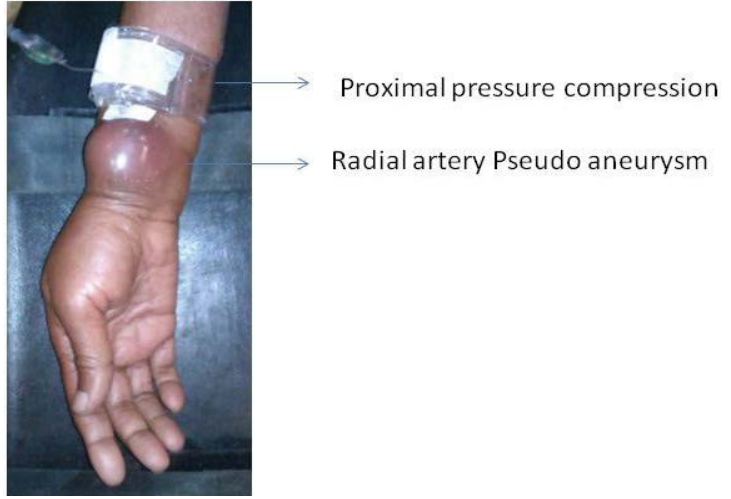

Figure 3: Radial Artery Pseudo Aneurysm Following Percutaneous TransRadial Coronary Angioplasty.

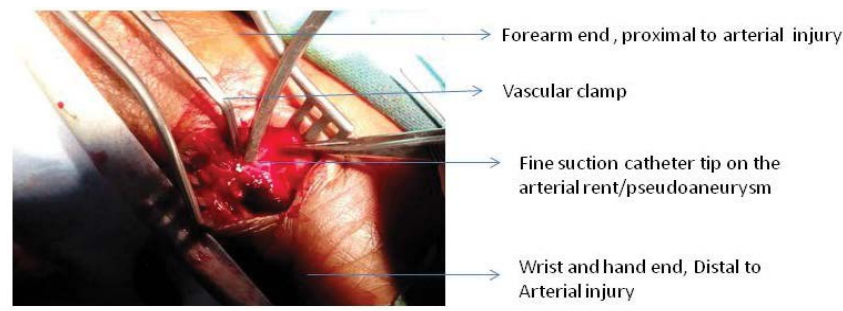

Figure 4: Surgical Repair of Radial Artery Pseudo-Aneurysm.

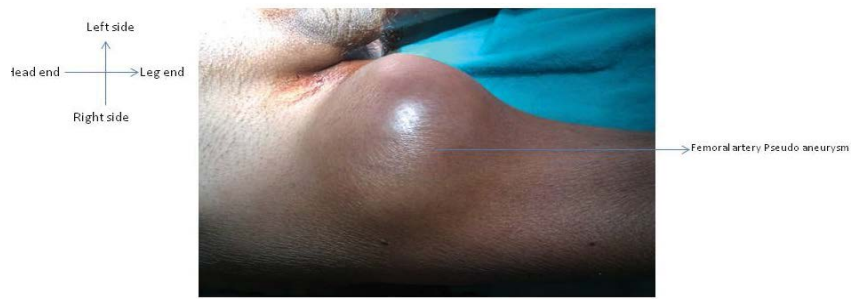

Figure 5: Right Femoral Artery Pseudo-Aneurysm Following Percutaneous Trans-Femoral Coronary Angioplasty.

it rises to $1 \%$ when femoral artery is used as access site for diagnostic procedure and $6 \%$ when the same is used to perform a therapeutic procedure $[7,8]$. Predisposing factors for complication at access site are; multiple punctures, high or low puncture site, ongoing systemic anticoagulation, inadequate post procedure compression, infection, use of large diameter sheath more than $8 \mathrm{Fr}$, complex interventions, obesity, age more than 65 yrs and systemic hypertension [5,9]. Most of these make femoral site more vulnerable for complications. Pseudo aneurysm is one of the most threatening complications mandating an immediate attention. While most of these, when diagnosed early can be managed conservatively by compression at the local site with or without ultrasound guidance or sometime by injecting thrombin as an added measure to compression technique [9]. Surgical repair of pseudo-aneurysm is indicated if it is infected, failure of other therapies, rapid expansion, skin necrosis, or compressive syndrome in the form of claudication, neuropathy, or critical limb ischemia [9].

Radial artery has a distinct advantage over femoral counterpart as it is located superficially and even a small swelling in this region will be noticed earlier. Moreover it is easier to control bleeding from the radial artery due to its anatomic location and relation to radial bone in vicinity. Radial artery posses an advantage over femoral artery of having luxurious collateral channels with ulnar artery and existence of deep and superficial palmer arches. These anatomical findings ensure safety of limb when radial artery need to scarified in some situations. However before embarking on surgery for radial artery pseudo aneurysm, evidence of patent palmer arches can be generated by a contrast CT or even with a Doppler ultrasound, which is safe and avoids contrast and radiation exposure.

In comparison a similar femoral artery pseudo aneurysm (Figure 5 ) is detected later in the course owing to its depth and relation to large muscles, fat and fascia. Constant compression of surrounding structure especially poorly vascularised fat, causes its necrosis and increases the chance of infection. These factors pose challenge to repairing a femoral artery pseudo aneurysm, which poses a definite threat to limb, as superficial femoral artery is sole supply to distal limb.

\section{Conclusions}

Radial artery pseudo aneurysm, though rare, can occur after coronary artery angiography or angioplasty through trans-radial route. Surgical management when indicated can be performed with good results under local anesthesia. They are always easy to manage (surgical management) in comparison with femoral counterpart with less threat to limb and life.

\section{Disclosures}

There is no conflict of interest of any author.

\section{References}

1. Lehmann R, Ehrlich JR, Weber V, de Rosa S, Gotarda MN, et al. (2011) Implementation of the transradial approach for coronary procedures is not associated with an elevated complication rate and elevated radiation patient exposure. J Interv Cardiol 24: 56-64.

2. Cooper CJ, El-Shiekh RA, Cohen DJ, Blaesing L, Burket MW, et al. (1999) Effect of transradial access on quality of life and cost of cardiac catheterization A randomized comparison. Am Heart J 138: 430-436.

3. Garg N, Madan BK, Khanna R, Sinha A, Kapoor A, et al. (2015) Incidence and predictors of radial artery occlusion after transradial coronary angioplasty: Doppler-guided follow-up study. J Invasive Cardiol 27: 106-112.

4. Indolfi C, Passafaro F, Mongiardo A, Spaccarotella C, Torella D, et al (2015) Delayed sudden radial artery rupture after left transradial coronary catheterization: a case report. Medicine 94: e634.

5. Kanei Y, Kwan T, Nakra NC, Liou M, Huang Y, et al. (2011) Transradial cardiac catheterization: a review of access site complications. Catheter Cardiovasc Interv 78: 840-846.

6. Sanmartín M, Cuevas D, Goicolea J, Ruiz-Salmerón R, Gómez $M$, et al (2004) Vascular complications associated with radial artery access for cardiac catheterization. Rev Esp Cardiol 57: 581-584.

7. Katzenschlager R, Ugurluoglu A, Ahmadi A, Hülsmann M, Koppensteiner R et al. (1995) Incidence of pseudoaneurysm after diagnostic and therapeutic angiography. Radiology 195: 463-466.

8. Kresowik TF, Khoury MD, Miller BV, Winniford MD, Shamma AR, et al. (1991) A prospective study of the incidence and natural history of femoral vascula complications after percutaneous transluminal coronary angioplasty. Journal of vascular surgery 13: 328-335.

9. Webber GW, Jang J, Gustavson S, Olin JW (2007) Contemporary management of postcatheterization pseudoaneurysms. Circulation 115: 2666-2674.

This article was originally published in a special issue, Coronary Artery Disease handled by Editor(s). Dr. Leonardo Silva Borges Roever, Federal University of Uberlandia (UFU) 